\title{
William Carlos Williams's Use of Voice in "To a Solitary Disciple"
}

JENNY SPENCER

An introduction to Williams's poetry via the Selected Poems can be confusing. Even with the background of Spring and All, which clarifies and demonstrates Williams's understanding of the creative imagination, it is difficult to discover the poetic ethic that can connect such widely differing poems as "Tract" and "The Red Wheelbarrow" or "The Trees" and "A Locust Tree in Flower." We could, of course, trace the different phases of Williams's career and note his own changing perception of what a poem should be; but the long poem Paterson which crowned his career seems to incorporate elements of many of the poems that came before. Moreover, despite the differences in tone, form, and syntax which indicate modifications in Williams's poetics, we have no trouble distinguishing his poems from those of Eliot or Crane. Williams always knew what a poem should not be. Luckily for us, he did not (and considering the literary climate of the time, could not) take his literary theory and practice for granted. Thus a poem like "To a Solitary Disciple" is helpful to the reader by virtue of addressing the subject of poetic practice while demonstrating the theory it expounds. On the one hand, it provides us with a perceptual lesson which is necessary to our understanding of his "objectivist" poems. But because it employs a persona, it can also tell us much about the status and use of voice, which is so important in poems like "Tract," "Death," and "Danse Russe."

The very title "To a Solitary Disciple" indicates that the poem's intention is instructive. The fact that the speaker has only one disciple not only gently undercuts any possibility of pretension on the poet's part, but also suggests that his audience is the solitary reader as well. ${ }^{1}$ And the lesson promises to be a personal one, a tête-à-tête between two friends ("mon cher"), not an impersonal lecture. The parallel gestures of the first three stanzas place us in the midst of an argument ("Rather notice ..."), the voice attempting to convince as well as in- 
struct. But the theoretical nature of the argument we gain only by induction. The speaker directs our attention and our eyes to the moon in an early morning sky above the steeple of a squat edifice; and in the act of naming he both creates and positions the objects in relation to each other on a flat two-dimensional plane. Jerome Mazzarro, in his brief discussion of the poem in William Carlos Williams: The Later Poems (pp. 54-55), describes the poem as an early cubist work which instead of being an invitation to descend, is an invitation to observe-the flatness of the landscape and parallelism in structure both tending to frame the work like a painting. But I don't think, as he does, that by framing the objects the poet has necessarily taken them "out of life," or is dealing with them as concepts in the same way he deals with "The Rose" image later. In fact, the speaker makes the objects "come to life" with the help of the perceptual imagination through the course of the poem.

Just what the speaker wants us to notice, to grasp, to see is made even clearer by its relation to what the listener has evidently already noted about the landscape (or perhaps in relation to what would conventionally be noted). ${ }^{2}$ The "disciple" would have us notice color, something Williams and the speaker do not find so important. Why? For one thing, such an observation takes no imagination. As a kind of scientific statement of fact:

\author{
It is true: \\ in the light colors of morning \\ brown stone and slate \\ shine orange and dark blue.
}

But so what? The tone implies that anyone can see this for himself, so who needs the poet? More importantly, color is not a palpable quality inherent in the thing itself; time of day adequately explains the orange and blue appearance and is therefore a more important detail to observe ("Rather observe that it is early morning ..."). Color does not contribute to the "thingness" of the objects described in the way that structure, shape, weight, and material do. Moreover, the colors assigned early in the poem to the moon and sky do not even have the virtue of appearing objective. Orange and blue are at least colors of the spectrum, while "shell pink" and "turquoise" are completely artificial. ${ }^{3}$ Interestingly, the use of color is one of Eliot's favorite poetic devices. Since it depends so much on subjective perception, he often uses it to reflect the persona's state of mind (usually depressed). That external reality should adequately reflect inner consciousness is a notion totally irrelevant to what Williams is trying to do. 
What the speaker does ask us to notice is the shape of things, their implicit structure, and most importantly, their relation to each other: "the moon is tilted above the point of the steeple," "the dark converging lines meet at the pinnacle," "lines of the hexagonal spire escape upward," etc. Static qualities are given, but the poet's imagination both seeks out and creates motion in the landscape-it is the interaction between the imagination and the objects which creates that movement. Williams's ontological relation to nature in his poems is important. He insists on the naked perception, things "out there," and energetically pushes to keep out the idea (or ideal). He would rather play the fool than the clever artificer, and yet he does not desire a purely sensual, unconscious relationship to the world, either. The worlds of his poems are not pantheistic universes ${ }^{4}$ where the self may be lost in nature (which even the Romantics finally realized was a phenomenological impossibility-death), but rather single moments in which the self is found (or founded) in its contact with the world. Consciousness exists only in its having an object, it is always consciousness of something; and in this light, the more distinct and palpable the object, the more fully alive the poet, conscious of the self in the act of perception/creation. In fact, if man is nothing but a relation to the world, then perception is the only act which undeniably affirms the self. And it is this active, naturally creative consciousness that Williams calls the imagination and the poems call forth in the reader. If we remember the shorter, more compact poems (those without a "voice"), we see even more clearly how this works. Consciousness exhausts itself in the positing of an object, but leaves the poem "charged" with that activity. And the reader reenacts his fundamental relation to the world as he reads the poem, being asked not "to think" (to drain the imagination in conceptual thought or cultural forms), but to perceive.

The lesson of "To a Solitary Disciple" is not only what to notice, but how to grasp it; and to really see you must "re-create" the objects with the imagination. For this reason, the movement of the poem is completely controlled by the persona, yet seems to be equally controlled by the objects of the landscape. Also, the entire poem is written in the imperative voice-we are being given directions, if not commands. There is no hesitancy on the speaker's part, no waffling around in vague poetic inspiration-he does not say "notice, if you can" but "look in front of you!" The landscape, even if "created" is not imaginary, but real. And yet the persona has a kind of visionary experience. In the literal sense of that term, he sees, and that sight is the contact of the imagination with external reality. 
See how it fails!

See how the converging lines

of the hexagonal spire

escape upward-

receding and dividing!

sepals

that guard and contain

the flower!

As indicated by punctuation and syntax, the result is a kind of climactic union. And the result of the union is a metaphor- "sepals"-not an insipid simile of the type offered by the disciple- "smooth as a turquoise." The reality of the "contact" is verified by the seeming spontaneity of the creation it inspires. Because the persona of the poem stands between us and the immediate contact, framing the activity if you will, he can also demonstrate the role of the imagination beyond simple perception. Thus, juxtaposition is the essence of his poetic method: not just to see, but to see things in relation.

But observe
the oppressive weight
of the squat edifice!
Observe
the jasmine lightness
of the moon.

It is not surprising, then, when we observe the importance Williams attaches to prepositions in his poems, often giving them whole lines to themselves. For it is this part of speech that indicates relation, where the imagination is most clearly at work positioning the surfaces of nature, selecting and arranging, positing absence as well as presence.

So far we have been talking about the speaker's aesthetic and its relation to Williams's own. But it is also necessary to consider the function of the voice itself and its relation to the poem. After all, the speaker is a persona, not a thinly disguised Williams handing us a magic key to the reading of his poetry. First of all, there is no attempt to individuate the voice-he is called into being by the specific needs of the poem and has no frame of reference outside the poem. The speaker enters a pre-existent field of a present moment-he is there to correct the specific errors of a particular disciple (whose mute existence is wholly contingent upon the persona), on a particular morning. And just as the landscape "read" by the voice will be a totally different landscape in the evening of the same day, so the speaker's words have a likewise tentative existence and are applicable only to 
the moment of the poem. ${ }^{5}$ The voice in Eliot's poems have a completely different ontology. In "The Love Song of J. Alfred Prufrock," each image is chosen to reinforce the never-stated psychology of the persona-the world-weary modern man. Prufrock's personality exists and colors everything it sees, so that the landscape is interiorized by the projected subjectivity of the poetic images. The two characters and the dramatic situation of "To a Solitary Disciple" are there to interpret the landscape, but the objects on that landscape are not there to tell us anything about the characters or their situation. There is no such thing as voice in the poem outside of its function. Like the imagination, the voice is simply a connective principle. The speaker causes us to read the poem in the same way he has made the implied disciple read the landscape. The voice teaches the reader to read the poem as a poet would read nature; for the poem is a landscape too, held together by linguistic relation. Williams wants our imagination to work on the poem, to make "contact" with it in the same way we would with any other external object. So the relation of the voice to the listener, for example, is just as important in the poem as the relation of the moon to the steeple. If we understand voice, then, as purely functional, as arising out of the particular needs of the present moment, created by the situation or objects within the field of the poem and making no referential sense outside the poem; then we can begin to get a notion of the use and function of persona in all of Williams's poetry.

1 "Tract" has a sententiousness about it, and it, too, promises instruction. Although on the one hand a rhetorical performance, a kind of harangue about the artificiality of funerals and the need for people to be more direct and spontaneous when dealing with death, it can also be read as another poem on poetry. Another poem, "The Wind Increases," which begins with a description of wind and is suddenly interrupted by "Good Christ, what is a poet-if any exists-" and is followed by the definition, is another example of Williams's use of a title to both describe and undercut. To suggest that the speaker himself is a bag of wind has negative as well as positive overtones. Playfulness is a quality inseparable from Williams's poetry.

2 For convenience's sake I will assume that the speaker is restating his implied "disciple's" previously spoken observation, since this is the dramatic situation the poem seems to indicate. I realize, of course, that the persona is the only voice in the poem and we can also assume that he is himself offering the "counter observations" for the purposes of comparison. Because of the linguistic medium, Williams is able to make us see what is not important as well as what is, but he uses these observations not to fill out the picture as we might expect, but to emphasize the relationship between the two sets of observations, and to undercut one with the other. 


\section{IOWA LITERARY STUDIES}

3 I might add that shell-pink and turquoise were also very prominent colors in fashionable clothes and jewelry of the '20s, suggesting the superficiality of color images. They are often merely decorative.

4 We should note that Williams seldom personifies nature. Rather, in "To a Solitary Disciple" he sees an "eaten moon"-an object capable of being humanly appropriated. The "lightness of the moon" is purely an imaginative quality, but corresponds to our ability to objectively perceive the weight of the "squat edifice"-again bringing the natural object within realm of human measurements and understanding without personifying.

5 Note that the time of the poem is early morning, the same "strange hour" that he keeps in "January Morning"-a time in which the moon can still be seen before it is erased by the broad daylight. The moment is therefore a fleeting one, despite the tendency of the poem to frame the moment and give it a permanent existence.

\section{The Day the People's Bank E Trust Caught Fire on the Forty Second Floor E They Threw the Money Down in Cheap Bank Bags}

Half way down their stuffed

Brown bellies tore.

Green feathers filled a

Section of sky.

Hundreds of wings without

A body flying down into

Smooth hands.

Smooth bodies tearing on

A sidewalk with green

Feathers pasted to their

Jagged skin like toilet tissue. 